NBSIR 77-1248

NTis pen D. Ballard 1/5/78. Un fo to bepart of SP-260 serues.

\title{
A Procedure for Calibrating the Magnification of an Scanning Electron Microscope Using NBS SRM 484
}

David B. Ballard

Metallurgy Division

Institute for Materials Research

National Bureau of Standards

Washington, D.C. 20234

June 1977

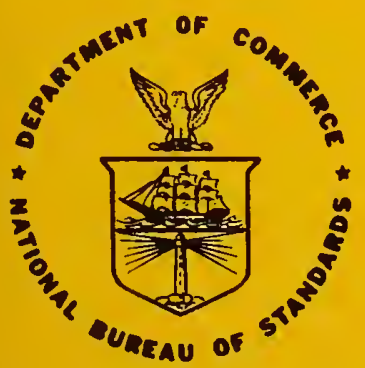

U. S. DEPARTMENT OF COMMERCE NATIONAL BUREAU OF STANDARDS 



\section{A PROCEDURE FOR CALIBRATING THE MAGNIFICATION OF AN SCANNING ELECTRON MICROSCOPE USING NBS SRM 484}

David B. Ballard

Metallurgy Division

Institute for Materials Research

National Bureau of Standards

Washington, D.C. 20234

June 1977

U.S. DEPARTMENT OF COMMERCE, Juanita M. Kreps, Secretary Dr. Sidney Harman. Under Secretary Jordan J. Baruch. Assistant Secretary for Science and Technology NATIONAL BUREAU OF STANDARDS, Ernest Ambler, Acting Director 

A Procedure for Calibrating the Magnification of

A Scanning Electron Microscope Using NBS SRM 484

David B. Ballard

A procedure for calibrating the magnification of a scanning electron microscope (SEM) is described in detail. The steps involved in specimen preparation and manipulation within the SEM are outlined. The SEM parameters that may have an effect on magnification are reviewed and techniques for correcting or minimizing these are presented. The photographic material used, image distortions recorded and technique of photograph measurement are discussed.

Keywords: Calibration; instrument parameters; magnification correction; photograph measurement; Scanning Electron Microscope; SRM 484 specimen preparation.

\section{INTRODUCTION}

Presently there are over 3,000 scanning electron microscopes (SEM) located in U.S. 1aboratories where research involves such topics as the study of air pollution particulates, corrosion of materials, wear of surfaces, fabrication of microelectronics and examination of microstructure of metals used in electrical energy distribution. An error of $10-30 \%$ within the magnification range of $1 \mathrm{KX}-20 \mathrm{KX}$ has been found to exist in some of these SEM's. Use of Standard Reference Material (SRM) 484 to calibrate the SEM magnification scale should reduce uncertainty to $5 \%$ or less in the range of 1 to $20 \mathrm{KX}$. This NBS Technical Note complements information issued with the SRM 484. A future NBS-260 series publication will contain details of the development and statistical evaluation of SRM 484.

\section{NBS - SRM 484}

\subsection{Fabrication and Calibration}

The initial step in fabrication of the SRM is to electroplate a layer of bright nickel onto the surface of a thin Monel sheet. Subsequently, alternate layers of bright gold (40-80 nm thick) and bright nickel (nominal thickness of $1,3,5$, and $20 \mu \mathrm{m}$ ) are deposited under precise control. A long-time, low-temperature vacuum anneal relieves stresses in the layers. Small, square $(9 \times 9 \mathrm{~mm})$ samples are sheared from the central portion of the composite sheet and mounted in copperfilled diallyl phthlate for metallographic polishing. The distances between the observed images of the gold lines are used to calibrate the magnification scale of the SEM (Fig. 1 and 2). The distance between adjacent gold lines was determined by comparison with a previously calibrated Master Standard that was measured by the NBS Dimensional Technology Section using a polarizing helium - neon laser interferometer. The uncertainty of this calibration, based on 81 independent measurements is $0.004 \mu \mathrm{m}$ for distances from 1 to $5 \mu \mathrm{m}$ and 


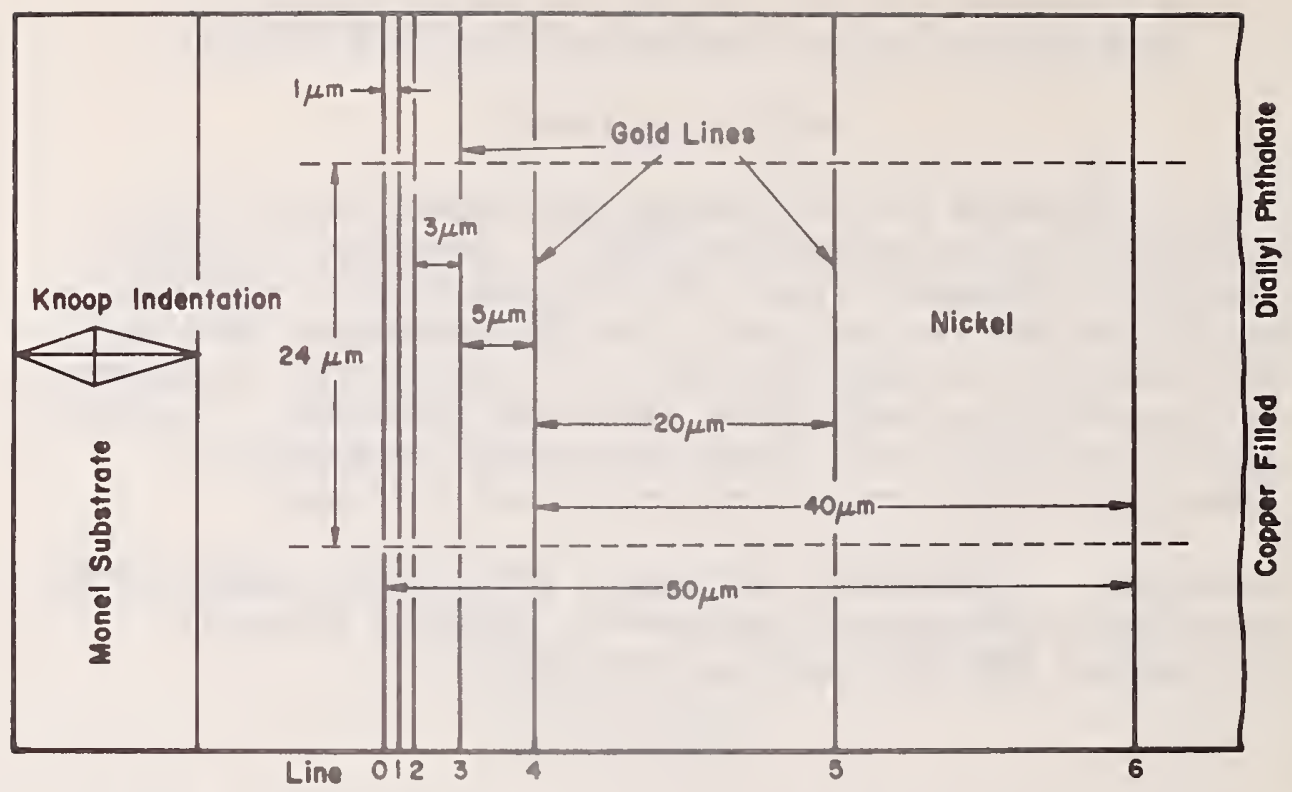

Fig. 1 SRM 484 is designed to calibrate the magnification scale of an SEM to an accuracy of $5 \%$ or better within the range of 1,000 to $20,000 \mathrm{X}$. The distance between gold line pairs $(0-1,0-2,2-3$, 3-4, and 0-6 nominally spaced at $1,2,3,5$ and $50 \mu \mathrm{m})$ located in a nickel matrix are individually calibrated. The calibrated area of $24 \mu \mathrm{m}$ is centered opposite the Knoop indentation placed at the mid-length of the specimen.

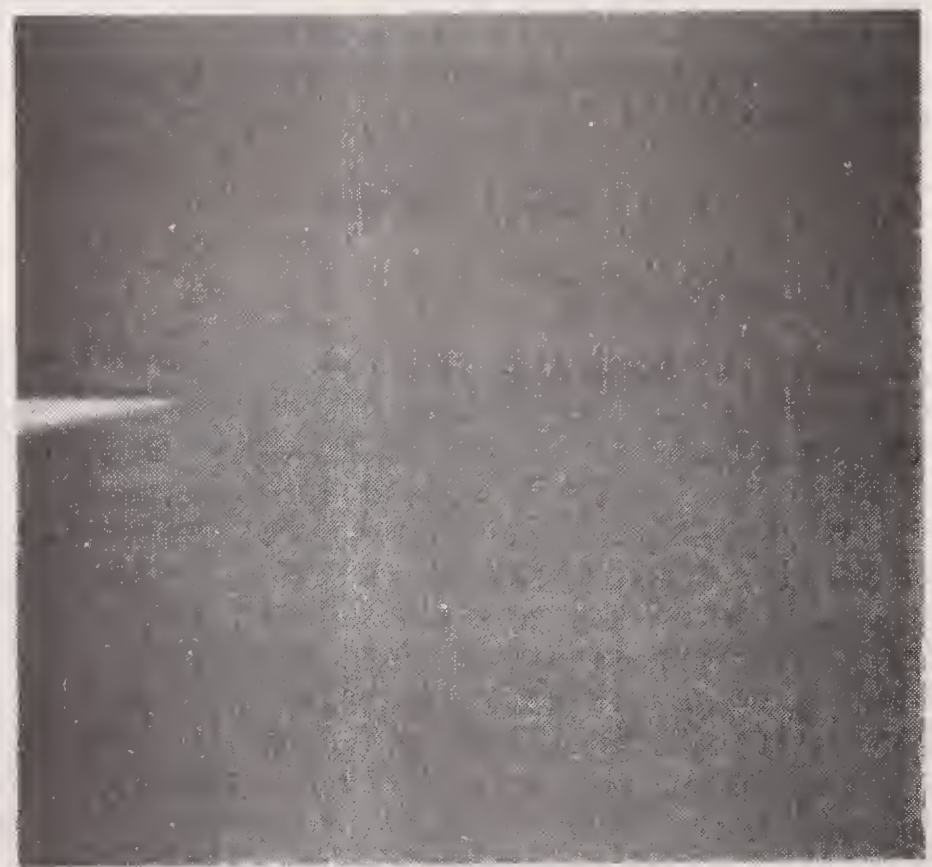

Fig. 2 Photomicrograph of SRM 484 showing images of line \#0 through 6 at a nominal magnification of $800 \mathrm{X}$. 
$0.009 \mu \mathrm{m}$ for distances from 10 to $50 \mu \mathrm{m}$. The total uncertainty for SRM 484 is $0.039 \mu \mathrm{m}$ for distances from 1 to $5 \mu \mathrm{m}$ and $0.71 \mu \mathrm{m}$ for distances from 10 to $50 \mu \mathrm{m}$. The calibrated line length of $24 \mu \mathrm{m}$ is centered opposite a Knoop indentation placed at the mid-length of the specimen.

\subsection{Specimen Preparation}

The SRM 484 specimen was mounted on an SEM stub with electrically conductive cement and dried in a vacuum oven at $60^{\circ} \mathrm{C}$ for 15 minutes. An alternative procedure was to clamp the specimen with set screws that were threaded into a modified SEM stub. Every effort was made to prevent relative motion or vibration between the stage and the electron beam. Lint and other loose debris were cleaned from the specimen surface with a blast of clean air before insertion into SEM specimen chamber. If additional cleaning was required to remove fingerprints, the specimen surface was gently swabbed with cotton saturated with a detergent solution. The detergent residue was removed by a water rinse, followed by a rinse with ethyl alcohol and clean air-blast dried.

Stubborn stains were removed with a minimum polish using metallographic grade $\mathrm{MgO}$ on microcloth, hand-held and stroking parallel to the gold lines. Any abrasive grinding of the polished surface would remove material in depth and subsequently change the calibrated line spacing. A good vacuum of $10^{-5} \mathrm{~mm}$ Hg was established before SEM examination to reduce surface contamination rates. This was desirable as contamination would decrease the contrast between the gold lines and the nickel matrix.

\section{SEM PARAMETERS}

The operational steps used to calibrate the magnification of each manufacturer's scanning electron microscope (SEM) are different and often do not consider all the instrument parameters which may change the resultant magnification (See Table). The following procedure details the use of NBS SRM 484, to calibrate one particular SEM*, but may be used as a guide for calibration of other SEM's.

\subsection{Outline of Procedure for Calibrating SEM Magnification Scale}

1. Rigidly mount SRM 484, whose surface has been inspected for cleanliness, on SEM stub with electrically conductive cement or clamp onto stage of SEM.

2. Surface of SRM 484 should be normal to electron beam.

3. A clean vacuum of $10^{-4} \mathrm{~mm}$ of $\mathrm{Hg}$ or better is necessary to keep the contamination rate on the surface of the SRM as low as possible.

4. Adjust electron gun voltage (between 5 to $30 \mathrm{kV}$ ), saturate filament, and check filament alignment.

5. Adjust final lens current at a resettable value. Cycle lens circuit OFF-ON 3 times to minimize hysteresis effects.

* Cambridge Stereoscan MK II. This instrument is identified solely for the purpose of describing the system used in this experiment. 
6. Allow a 30 minute or more warm-up of electronic circuits to achieve operational stability.

7. Adjust lens apertures and stigmator for optimum resolution (minimum astigmatism).

8. SEM resolution should be a minimum of $0.05 \mu \mathrm{m}$.

9. Position the SRM-484 specimen at a nominal magnification of $1 \mathrm{KX}$ so that the image of the Knoop indentation is centered at one edge of the viewing CRT. The width of the gold-line calibrated area extends $12 \mu \mathrm{m}$ above and below this indentation.

10. a) The same working distance or magnification scale of the SEM can be reproducibly obtained by focusing on the image of the gold lines with $Z$ axis control at highest possible magnification to minimize depth focus. An alternate focus method is to use " $y$ " mode and adjust $Z$ axis for maximum signal. b) To minimize the effect of distortions produced by the recording system, the SRM-484 can be substituted and photographed for the unknown sample. Specific lines on SRM 484 to be used in the calibration should be chosen so that the distance between them corresponds as closely as possible to the length of the object to be measured with both images positioned in the same area on the cathode ray tube (CRT). A millimeter scale taped onto the edges of the CRT of the $x$ and $y$ directions will assist in the relocation on the respective images.

11. Add "Black Level" for contrast if necessary, S/N ratio should be $2: 1$ minimum.

12. Allow Polaroid prints to dry 15 to 20 minutes or more to minimize effects due to emulsion and coating shrinkage.

13. Measure the perpendicular distance between the lines using center of each line image on the photograph with a TEM Diffraction Plate Reader or use an equivalent instrument the precision of which is suitable for this purpose (about $0.2 \mathrm{~mm}$ ).

14. Repeat measurements 3 times on each photograph to determine the average spacing.

15. Magnification $=\frac{\text { Distance between lines as measured on photograph }}{\text { Certified distance between same lines }}$

16. To determine SEM stability and reproducibility, repeat all steps at hourly or daily intervals or after adjustments and repairs.

Some of the above parameters that effect magnification will be briefly reviewed and discussed with examples. It is assumed that a11 electronic signal detection and processing components of the SEM involved are within manufacturer's operating specifications.

\subsection{Specimen Stage Controls}

The controls of the SEM stage should allow substitution of SRM 484 for the unknown specimen without changing or interruption of the electronic circuits. Thus, it is necessary to mechanically refocus onto the surface of each specimen using the $z$ axis (working distance) stage micrometer. Calibration is most easily accomplished with the specimen 
oriented at right angles to the electron beam. However, if a tilted surface is necessary for sufficient secondary electron signal, only the central portion of the photo with the gold lines parallel to the tilt axis of the stage can be considered as the calibrated area. Magnification values on other axes are subject to error due to foreshortening, particularly at low magnifications and at high tilt angles. Of course, SRM 484 could be used to measure the amount of foreshortening if the specimen surface orientation is known.

\subsection{Image Drift}

Apparent electronic circuit instability may be observed even after a 30 minute warm-up period. This may be due to three parameters of the SEM that can have a major short term (less than one hour) effect on the magnification. These are (1) lens hysteresis, (2) the electron-gun high voltage power supply, and (3) scan coils including related scangenerator circuits. To stabilize the magnetic lenses, it is recommended that they be cycled ON-OFF at least twice or until the observed image remains in focus and image displacment is minimized at the highest magnification to be calibrated. Some electron tube circuits of parameters (2) and (3) have less electronic stability than solid state circuits.

Other sources of image instability are specimen surface contamination, aperture contamination, stage creep, and continuous thermal drift of electron column parts. All of these parameters should be considered, controlled if possible, and compensated for by the operator. For example, an image position drift of $7 \mu \mathrm{m} /$ hour, using one line of the SRM 484 as an index, has been observed at $20,000 \mathrm{X}$ in the SEM used in this work. This drift is not serious if the scan line direction is perpendicular to the gold line axis and for the following reasons. The exposure time for one photograph was 40 seconds. The total height of the image field was $90 \mathrm{~mm}$, but only a $3 \mathrm{~mm}$ segment of the image line length was used for reference measurements. This segment represented $\simeq 1.3$ seconds of scan time equivalent to $\simeq 2.6 \mathrm{~nm}$ drift. A displacement of this magnitude was below the SEM resolution and was therefore considered negligible.

\subsection{Magnification Drift}

A separate magnification correction may be necessary for any change in operation parameters. As an example, each magnification range must be examined where a change of fixed resistors is involved. However, over a long term (more than 1 hour) magnification calibration of the SEM can change. For example, a change was documented by locating a precise area on the SRM 484 specimen and photographing this area at three different magnifications over an extended time period. This technique was applied at frequent daily intervals over approximately five months. The results of these observations showed a maximum of $0.6 \%$ change for a nominal $2 \mu \mathrm{m}$ and a $5 \mu \mathrm{m}$ space recorded at 20 and $10 \mathrm{KX}$. The amplitude and sign of change in magnification varied in a 
nonsystematic fashion with time. The instrument operation covered the normal work period hours and included many operators using various modes of SEM operation.

\subsection{Resolution}

At least $50 \mathrm{~nm}$ resolution was found necessary to have a sufficiently sharp image of the gold lines of SRM 484 so that measurements could be made from line-center to line-center. This procedure allowed a precision of $\pm 0.2 \mathrm{~mm}$ on measurements of the spacing on photomicrographs between lines \#0, 1 and 2. A typical photo recorded at nominal magnification of 20,000 X demonstrates this quality of image and is shown in Fig. 3 . Available resolution test materials such as NBS RM-100 (aluminum tungsten dendrites), magnetic tape, copy paper and etched gold grid may be employed to assist in the adjustment of minimum astigmatism, alignment of apertures, selection of lens currents, and signal processing, prior to magnification calibration.

\subsection{Recording Photographic Material}

The photographic material used here was Polaroid* type \#52 film. The ASA rating of 400 and contrast latitude of this film produced good contrast images of the gold lines. The short development time after exposure was a convenience that allowed images to be measured. After exposure, the prints were processed and coated as specified by the manufacturer. The photo emulsion was allowed to dry and equilibrate for a minimum of 20 minutes before measurements were made. No significant difference in line spacing was noted due to a longer drying time or temperature and humidity changes normally experienced in laboratory room conditions. Other fine grain photographic products could be used if appropriate care is exercised.

\subsection{Recorded Image Distortion}

As a result of distortions within the recording CRT and the camera photo lens, the magnification of an image near the print edges or at other locations on the photo may be erroneous as compared to that in the calibrated area. This magnification distortion is independent of specimen tilt angle or signal processing. The amount and location of distortion can be surveyed and measured by displacing, at $5 \mathrm{~mm}$ intervals on the SEM recording screen, the appropriate gold line space of SRM 484 at magnifications of $1 \mathrm{kX}$ to $20 \mathrm{kX}$. A photo recording is made at each interval. The same calibration space between the gold lines is measured and the correction is applied to the indicated instrument scale or photo area.

\footnotetext{
*Polaroid - This product is identified solely for the purpose of describing the material used in this procedure.
} 


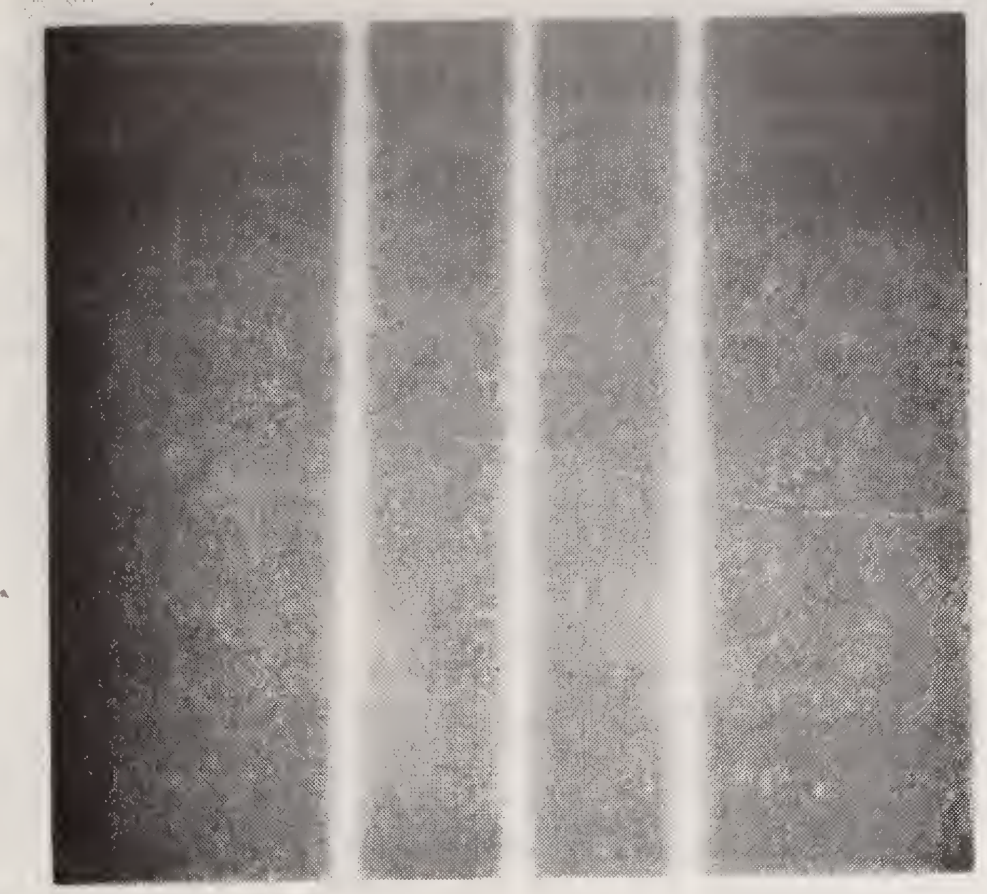

Fig. 3 Photomicrograph of SRM 484 showing the images of lines \#0, 1 and 2 at a nominal magnification of $20,000 \mathrm{X}$.

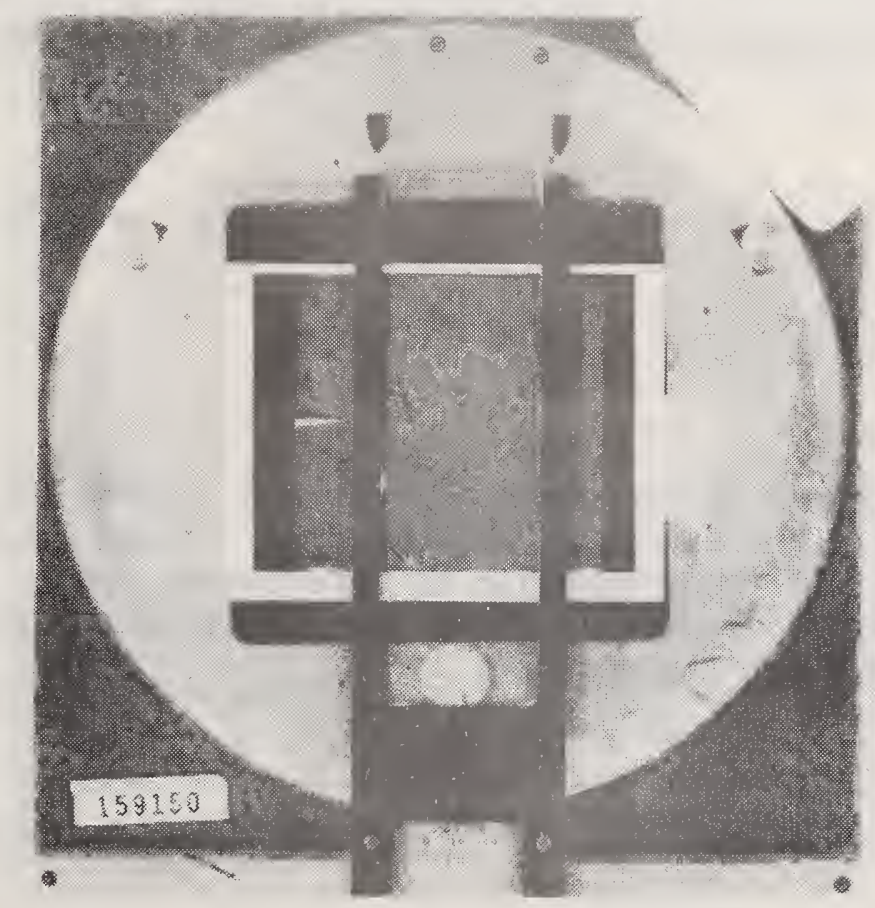

Fig. 4. Photo-reader used to measure space between line images. 


\subsection{Photographic Measurements}

To reduce errors which may be as much as $\pm 0.5 \mathrm{~mm}$ due to photo placement onto the photo reader, a mark was placed on the face of the CRT so that on each recorded photo this fiduciary could be used as an index (Fig. 4). Measurements of the space between line-centers on the photo must be made perpendicular to the line length.

An average value for each line spacing was determined from a minimum of three measurements made on each photograph. This value was then corrected for photo-field distortion, which could be as much as $15 \%$ and is shown in line \#6 of Fig. 2. The correction applied to the measured data was of the form $f(x)=a+b x+c x^{2}$ (a parabola). For the SEM used in this study, the image area having least distortion was found to be offset $5 \mathrm{~mm}$ to the right of the photograph center.

\section{CONCLUSIONS}

An independent (closed Loop) check on a11 the above magnification correction procedures was made. The line spacings of one SRM 484 specimen were measured with the same accurate polarized laser interferometer that was used to calibrate the Master Standard. The values determined for line spacings of $1,2,3,5$ and $50 \mu \mathrm{m}$ agreed within 2.5\% (probable error) of those obtained using the SEM.

If the above SEM parameters were properly controlled and a specimen of SRM 484 used, the magnification scale of this SEM could be calibrated to an uncertainty of $5 \%$ or less between the range of $1 \mathrm{kX}$ and $20 \mathrm{kX}$. Extension of this method should be applicable to other SEM instruments.

Disclaimer:

Certain trade names and company products are identified in order to adequately specify the experimental procedure. In no case does such identification imply recommendation or endorsement by the National Bureau of Standards nor does it imply that the products are necessarily the best available for the purpose. 
1. Photographic material - shrinkage/expansion, photographic enlarging.

2. Recording camera-lens distortions, and change of CRT image size.

3. Recording CRT - distortion of faceplate, and beam deflection.

4. Scan generator - nonlinearity, and aging components.

5. Scan coils - nonorthogonal.

6. Magnification switch resistor chain - different for each magnification.

7. Zoom control on magnification - resettability

8. Working distance - long (small angle beam deflection) vs. short (large angle beam deflection) for same magnification.

9. Specimen tilt - not perpendicular to beam.

10. Specimen tilt correction - relative to tilt axis.

11. Specimen image drift - charging or stage drift.

12. Depth of focus

13. Reproducibility of specimen height control.

14. Lens strength combinations - particularly for three lens instruments.

15. Lens astigmatism and hysterisis.

16. Electron gun stability.

17. Extraneous magnetic and electrostatic fields. 


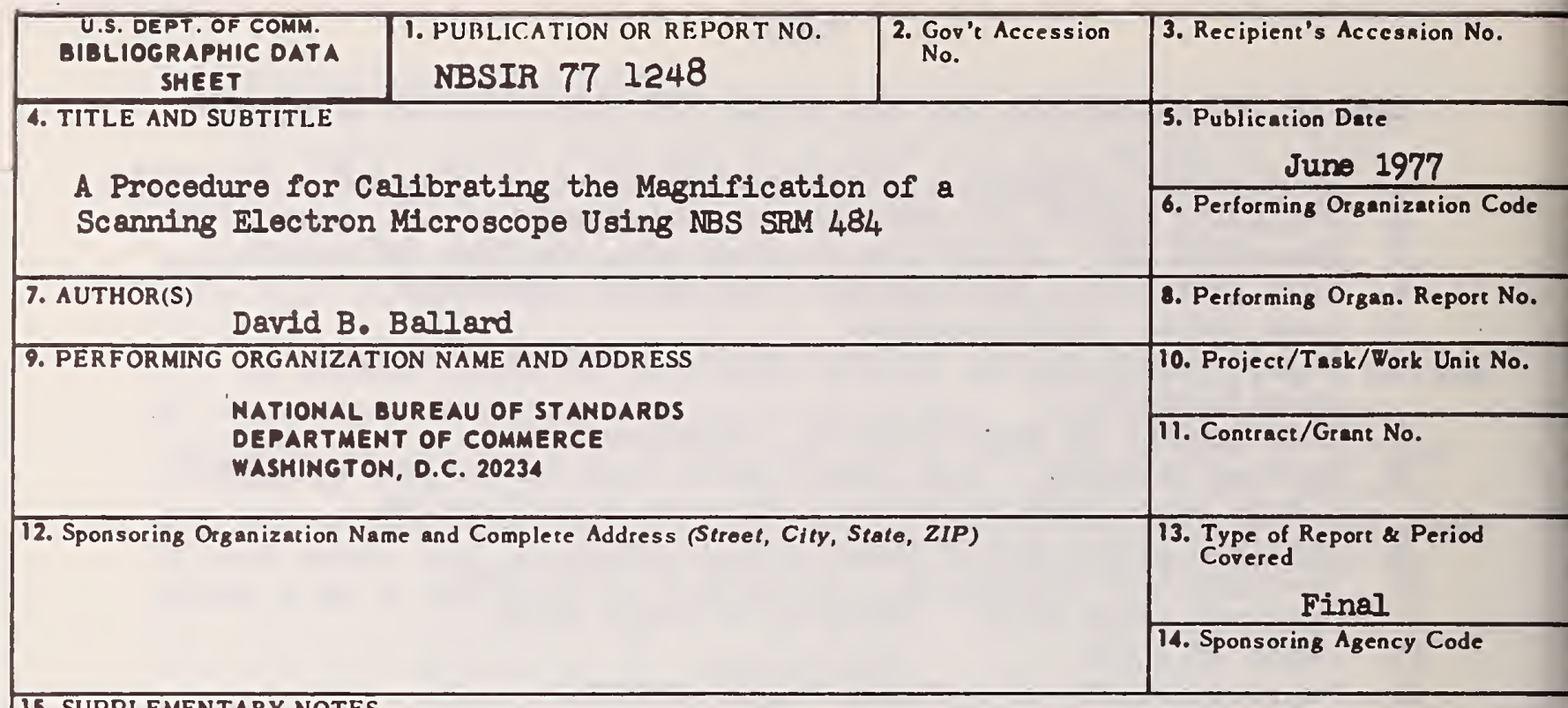

15. SUPPLEMENTARY NOTES

16. ABSTRACT (A 200.word or less factual summary of most significant information. If document includea a elenificant bibliography or literature survey, mention it here.)

A procedure for calibrating the magnification of a scanning electron microscope (SHM) is described in detail. The steps involved in specimen preparation and manipulation within the SEM are outlined. The SRM parameters that may have an effect on magnification are reviewed and techniques for correcting or minimizing these are presented. The photographic material used, image distortions recorded and technique of photograph measurement are discussed.

17. KEY VORDS (six twelve entries; alphabetical order; capitalize only the first letter of the first key word unless a proper name; sepurated by semicolons)

Calibration; instrument parameters; magnification correction; photograph measurement; scanning electron microscope; SRM 484 speciment preparation.

18. AVAILABILITY

For Official Distribution. Do Not Release to NTIS

[X Order From Sup. of Doc., U.S. Government Printing Office Washington, D.C. 20402, SD Cat. No.C13 146.951

Order From National Technical Information Service (NTIS) Springfield, Virginia 22151

\begin{tabular}{|c|c|}
\hline $\begin{array}{l}\text { 19. SECURITY CLASS } \\
\text { (THIS REPURT) } \\
\text { UNCL ASSIFIED }\end{array}$ & $\begin{array}{l}\text { 21. NO. OF PAGES } \\
12\end{array}$ \\
\hline $\begin{array}{l}\text { 20. SECURITY CLASS } \\
\text { (THIS PAGE) } \\
\text { UNCLASSIFIED }\end{array}$ & $\begin{array}{l}\text { 22. Price } \\
\qquad 3.50\end{array}$ \\
\hline
\end{tabular}

